\title{
Characterization of Plasma Parameters and Tissue Injury Produced by Plasma Electrosurgical Systems
}

\author{
J. Canady, ${ }^{a *}$ A. Shashurin, ${ }^{b}$ K. Wiley, ${ }^{a}$ N. J. Fisch, ${ }^{c}$ \& M. Keidar ${ }^{b}$ \\ aJerome Canady Research Institute for Advanced Biological and Technological Sciences, 6930

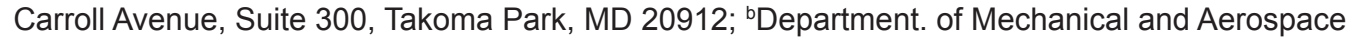 \\ Engineering, George Washington University, Washington, DC 20052, USA; 'Department of Astro- \\ physical Sciences, Princeton University, Princeton, NJ 08543
}

\footnotetext{
* Address all correspondence to: Jerome Canaday, Jerome Canady Research Institute for Advanced Biological and Technological Sciences, 6930 Carroll Avenue, Suite 300, Takoma Park, MD 20912.

Email: drjcanady@usmedinnov.com
}

\begin{abstract}
Plasma and injury properties produced by US Medical Innovations (USMI) electrosurgical systems were characterized using an explant pig's liver samples. It was observed that plasma length, tissue temperature, and injury size increases with applied power increase. Transition from conventional to argon coagulation mode $(<0.5 \mathrm{~L} / \mathrm{min})$ leads to redistribution of the discharge power over the larger tissue area causing abrupt decrease of injury depth and increase of eschar diameter. Flow rate is not a primary factor affecting the tissue temperature. The depth and diameter of injury was minimal for the case of hybrid argon plasma cut operational mode.
\end{abstract}

\section{INTRODUCTION}

Application of plasma in medicine has a long history and it primarily relies on the thermal effects of plasma. ${ }^{1}$ In this respect, heat and high temperature have been utilized in medicine for a long time for the purpose of tissue removal, sterilization, and cauterization. One of the successful applications of thermal plasma is argon plasma coagulation (APC) in which highly conductive plasma allows passing a current through the tissue. ${ }^{2}$ APC is being used to cut tissue and, in particular, for endoscopic applications. $^{3}$

Currently plasma-based electrosurgery has been established in many surgical subspecialties. To this end various electrode configurations have been used, such as a monopolar high-frequency probe, a bipolar coaxial head, and side-fire probe. The following important features assure success of the electrosurgery devices: high precision, reproducibility, control of the depth, and coagulation.

In this paper we evaluated the basic plasma properties and injury characteristics produced by the plasma electrosurgical systems SS-200E/Argon 2 and SS-601MCa/Argon 4 of US Medical Innovations. Dependence thermal effects induced in living tissue on operational conditions are analyzed. 


\section{MATERIAL AND METHODS}

All experiments were carried out on an explant pig's liver samples. Immediately after testing the liver samples were placed in $10 \%$ formalin solution, $\mathrm{pH} 7.0$, for $24 \mathrm{~h}$, and sent for Hematoxylin and Eosin (H \& E) preparation of the pathological slides. Experiments were conducted using USMI's SS-200E/Argon 2, and the SS-601MCa/ Argon 4 was used in combination with Canady Vieira Hybrid Plasma ${ }^{\mathrm{TM}}$ Scalpel. Four high-frequency operation modes were tested, namely Conventional Cut, Conventional Coagulation, Argon Plasma Coagulation, and Hybrid Argon Plasma Cut. Note, the term "conventional operation mode" refers to the treatment without argon.

Plasma length, tissue heating, diameter of eschar, and depth of injury were measured. The length of the plasma was characterized by the maximal length of the discharge plasma column observed at tissue treatment at which the discharge can be stably sustained. The treatments were video recorded by digital camera, Nikon Coolpix 995 (15 frames/s), and the maximal length of the discharge plasma column $(L)$ was measured by post-experiment evaluation of recorded videos.

The sample temperature was measured using the thermocouple (Type K) probes embedded in the pig's liver. In coagulation mode, the pig's liver sample was treated by five consecutive applications of the Canady Vieira Hybrid Plasma ${ }^{\mathrm{TM}}$ Scalpel to the same point of the liver sample (total treatment duration $\sim 5 \mathrm{~s}$ ). The thermocouple was located about 3 mm under the treated point as shown in Fig. 1(a). In cut mode, a 5-mm straight cut in the pig's liver sample was created by five consecutive passes with the Canady Plasma Scalpel along the cut (total duration $\sim 5 \mathrm{~s}$ ) and the thermocouple probe was located about $3 \mathrm{~mm}$ away from the cut [see Fig. 1(b)]. The accuracy of temperature and length measurements were $5^{\circ} \mathrm{C}$ and $0.5 \mathrm{~mm}$, respectively. Tissue temperature prior to treatment was $18-20^{\circ} \mathrm{C}$.

Immediately after treatment the liver samples were placed in $10 \%$ formalin solution, $\mathrm{pH}$ 7.0, for $24 \mathrm{~h}$ and sent for $\mathrm{H} \& \mathrm{E}$ preparation of the pathological slides. Pathologists used a Moticam Camera 1000, 1.3, and an Olympus Microscope Bx 41 to calculate the depth of injury. Eschar diameter produce by the plasma scalpel blade was measured using a digital caliber (see Fig. 2).

\section{RESULTS AND DISCUSSIONS}

\section{A. Tissue Heating Measurements}

Tissue temperature increase (DT) as result of treatment vs. applied power in Coagulation mode is presented in Fig. 3 for SS-200E/Argon 2 and SS-601MCa/Argon 4. One can see that change of gas flow does not have a definite effect on the tissue heating. Also, the growing trend of tissue heating with power increase was observed for SS-601MCa/ Argon 4, as opposed to SS-200E/Argon 2 where similar tissue heating values were observed regardless of the power level.

Tissue heating as result of treatment vs. applied power in Cut mode is presented 

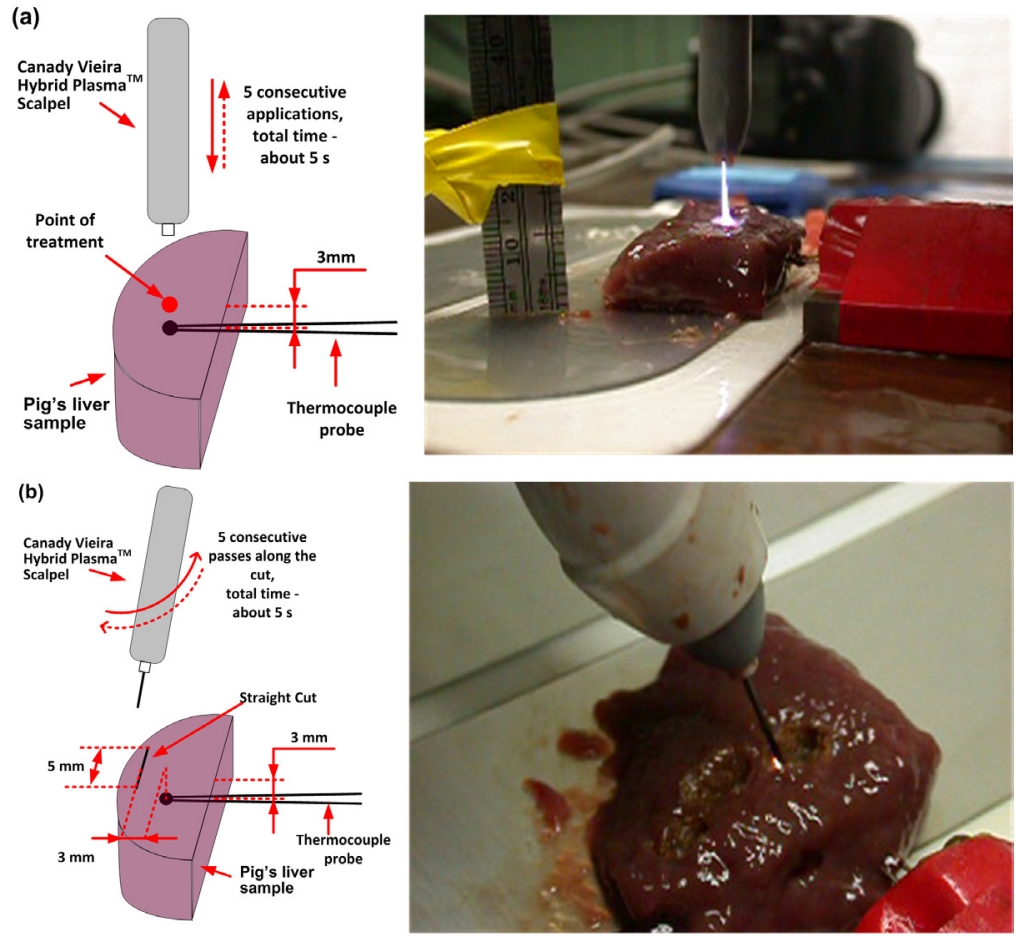

FIG. 1: Schematics and photographs of the temperature measurement: (a) Coagulation mode; (b) Cut mode
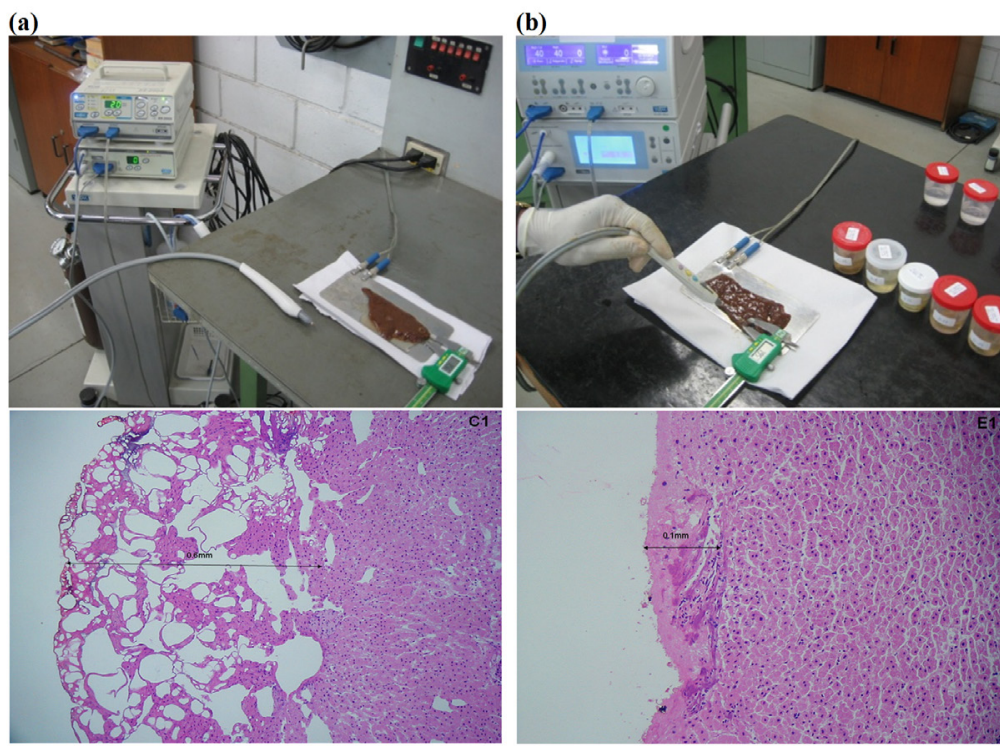

FIG. 2: Pathological studies of tissue injury depth: (a) Argon Coagulation mode (SS-200E/Argon 2, $20 \mathrm{~W}, 0.5 \mathrm{~L} / \mathrm{min}$ ); (b) Argon Cut mode (SS-601Mca/Argon 4, 20W, $0.1 \mathrm{~L} / \mathrm{min}$ ) 

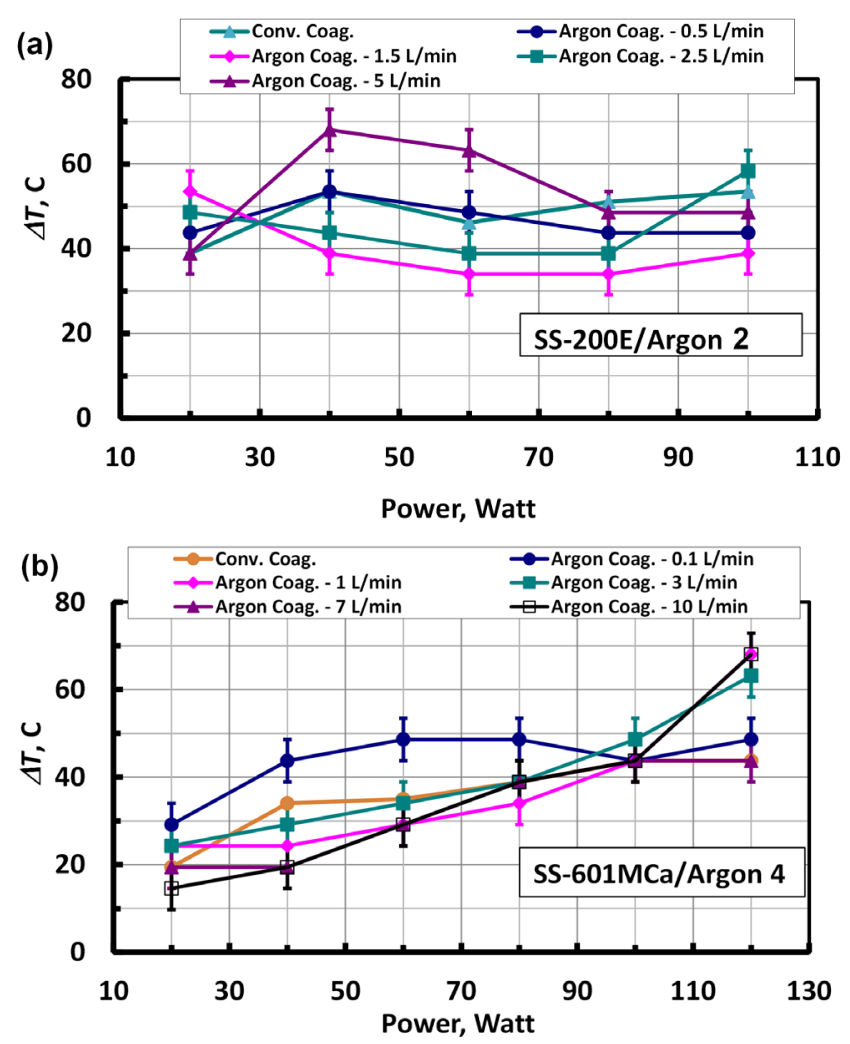

FIG. 3: Tissue heating as function of power in Coagulation mode using (a) SS-200E/Argon 2; (b) $\mathrm{SS}-601 \mathrm{MCa} /$ Argon 4

in Fig. 4 for SS-200E/Argon 2 and SS-601MCa/Argon 4. Both electrosurgical systems caused elevated temperature change DT with power increase, while SS-200E/Argon 2 generally led to about $20^{\circ} \mathrm{C}$ stronger temperature increase compared to SS-601MCa/ Argon 4.

\section{B. Plasma Length Measurements}

Plasma length was only measured in Coagulation mode, since Cut mode is associated with direct contact of scalpel with tissue (plasma length did not exceed 1-2 mm). Maximal plasma length in Coagulation mode measured as a function of applied power for SS200E/Argon 2 and SS-601MCa/Argon 4 is shown in Fig. 5. It was observed that plasma length always increased with power. The longest plasma length of about $2 \mathrm{~cm}$ was achieved using the SS-601MCa/Argon 4 electrosurgical system. It was also observed 
that low argon flow values of $\leq 0.5 \mathrm{~L} / \mathrm{min}$ (and Conventional Coagulation mode) yielded relatively small plasma lengths less than $4 \mathrm{~mm}$, while increase of argon flow to about 1 $\mathrm{L} / \mathrm{min}$ led to about a fourfold increase of plasma length. A further increase of argon flow $>1 \mathrm{~L} / \mathrm{min}$ did not result in significant change of plasma column length.

\section{Injury Measurements: Diameter of Eschar}

The diameter of eschar produced at tissue treatment in Coagulation mode with the SS200E/Argon2 electrosurgical system as a function of applied power is presented in Fig. 6 for different gas flow rates. One can see that the diameter of the eschar increased with applied power level. In addition, it was observed that increase of gas flow led to abrupt increase of eschar diameter at the transition from Conventional to Argon Coagulation (from $0 \mathrm{~L} / \mathrm{min}$ flow to $0.5 \mathrm{~L} / \mathrm{min}$ ), while further increase of the gas flow $(>0.5 \mathrm{~L} / \mathrm{min}$ ) did
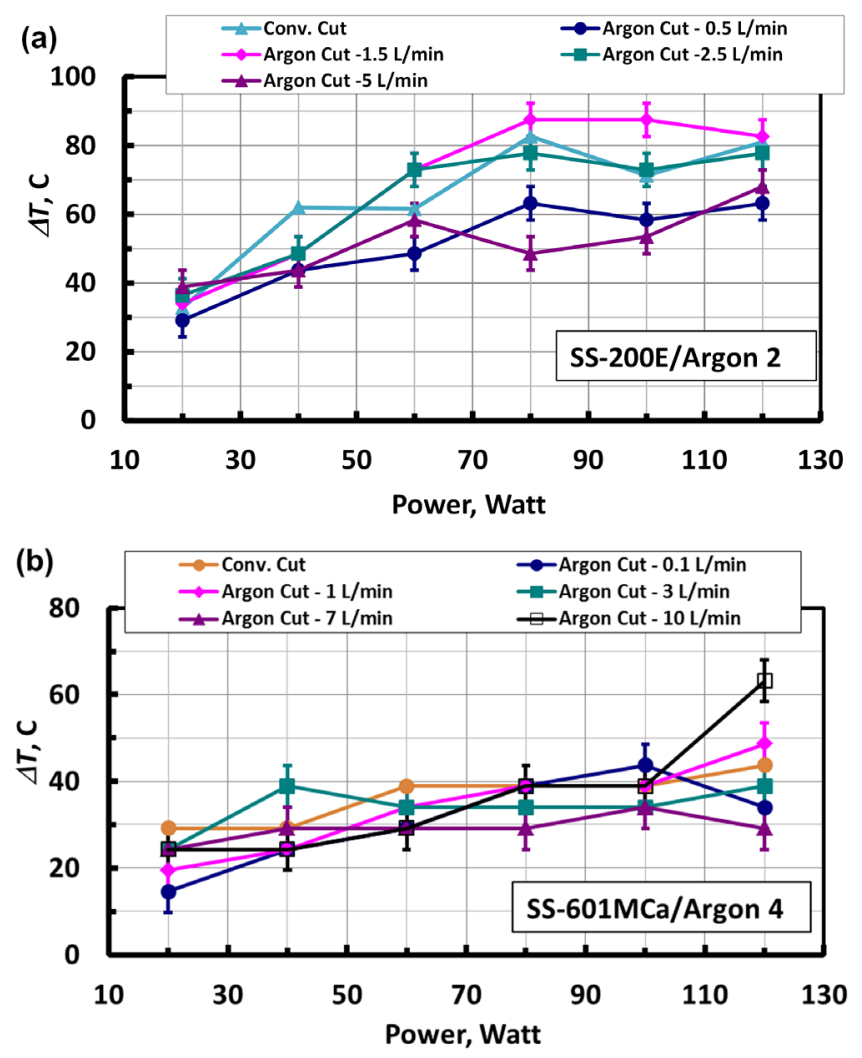

FIG. 4: Tissue heating as function of power in Cut mode using (a) SS-200E/Argon 2; (b) SS$601 \mathrm{MCa} /$ Argon 4 

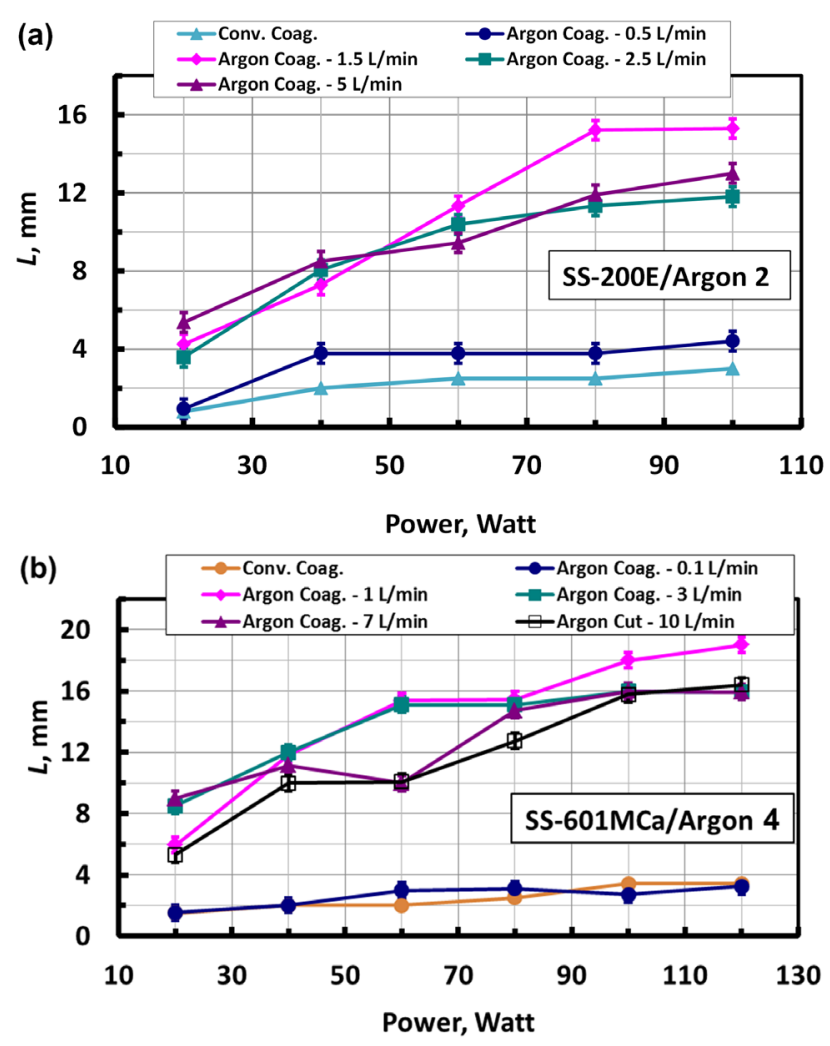

FIG. 5: Maximal plasma length as function of power in Coagulation mode using (a) SS-200E/ Argon 2; (b) SS-601MCa/Argon 4

not affect the injury diameter significantly. In contrast to Coagulation mode, the diameter of the eschar produced in Cut mode was observed to be not sensitive to the gas flow rate and demonstrated just a slow increase with applied power level as shown in Fig. 7.

\section{Injury Measurements: Depth of Eschar}

Depth of eschar produced at tissue treatment in Coagulation mode with SS-200E/Argon2 electrosurgical system as function of applied power is presented in Fig. 8 for different gas flow rates. The main trend of eschar increase with applied power was conserved. However, increase of gas flow led to abrupt decrease of eschar depth just at the transition from Conventional to Argon Coagulation (see "Conv. Coag." and "Argon Coag." at 0.5 $\mathrm{L} / \mathrm{min}$ in Fig. 8). A further increase of the gas flow $(>0.5 \mathrm{~L} / \mathrm{min})$ did not cause significant 
change of eschar depth. Corresponding dependencies obtained in Cut mode showed increase of eschar depth with power and fair independence on gas flow (see Fig. 9).

\section{DISCUSSION}

The results provide extensive data for comparison of various parameters and operation conditions of SS-200E/Argon 2 and SS-601MCa/Argon 4 electrosurgical systems. Generally, increase of applied power led to increase of tissue heating, plasma length, and injury size which is caused by increasing the power that is absorbed by the tissue. Both electrosurgical systems demonstrated similar trends and rates of the parameter change at power increase.

The study examined the effect produced by changing the gas flow. The abrupt reaction of measured tissue parameters at the transition from Conventional Coagulation to Argon Coagulation mode was found. The experimental data demonstrate $30 \%-60 \%$ increase of eschar diameter at slight increase of gas flow from Conventional Coagulation (no gas flow) to low flow $(<0.5 \mathrm{~L} / \mathrm{min})$ in Argon Coagulation mode. In contrast with the injury diameter, the plasma length and the injury depth decreased about four times at the transition to low flow Argon Coagulation mode. Tissue temperature at the same time did not demonstrate significant change with gas flow. Interestingly, a further increase of gas flow $>0.5-1 \mathrm{~L} / \mathrm{min}$ did not result in significant change of the parameters.

The observed phenomenon is caused by threshold change of plasma dynamics at transition to Argon Coagulation mode and improving capability to sustain the discharge. Indeed, argon addition to the discharge removes oxygen from the discharge zone, which is well known to be a main reason for quenching the plasmas. ${ }^{4}$ Therefore, even a small addition of argon results in a significant increase of plasma column length observed in experiment (experimental data indicate that the threshold value of the argon flow is

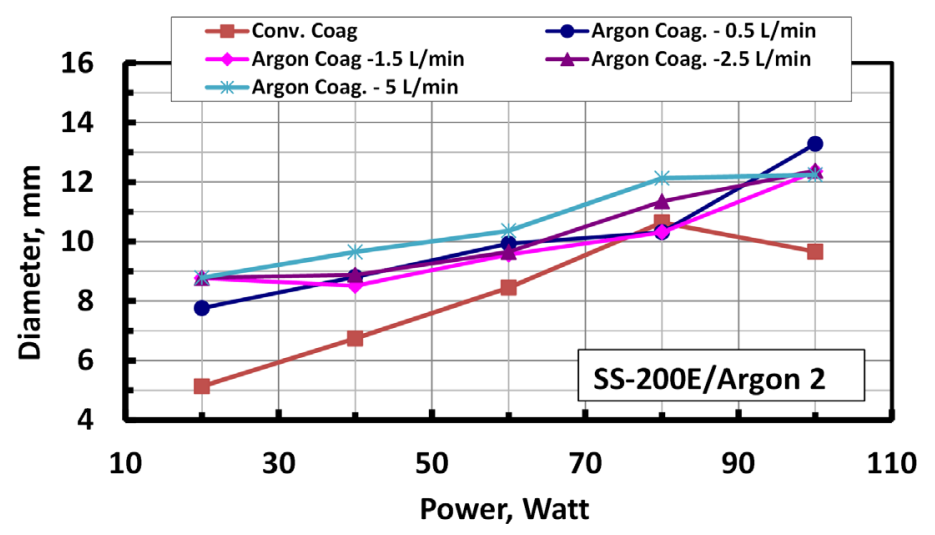

FIG. 6: Diameter of eschar in Coagulation mode using SS-200E/Argon 2 

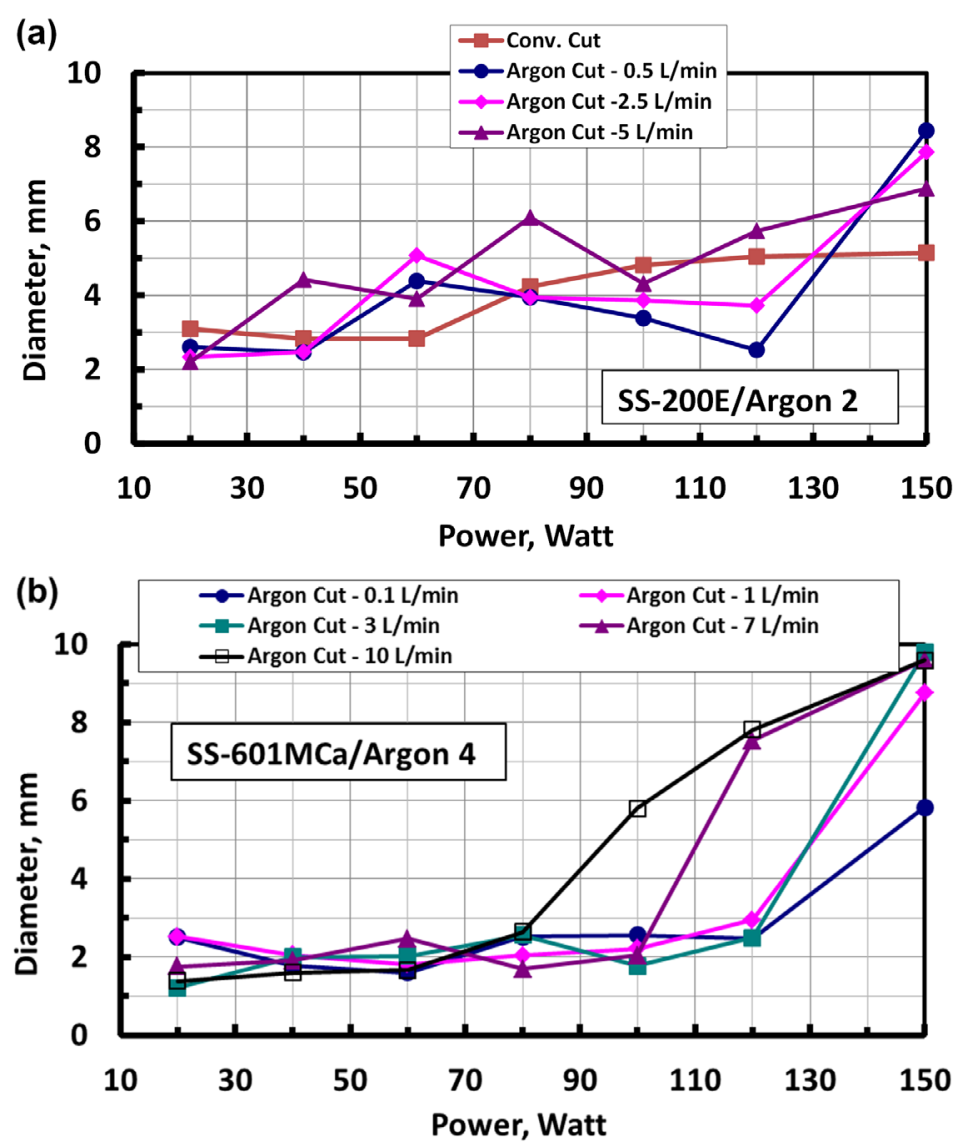

FIG. 7: Diameter of eschar in Cut mode using (a) SS-200E/Argon 2; (b) SS-601MCa/Argon 4

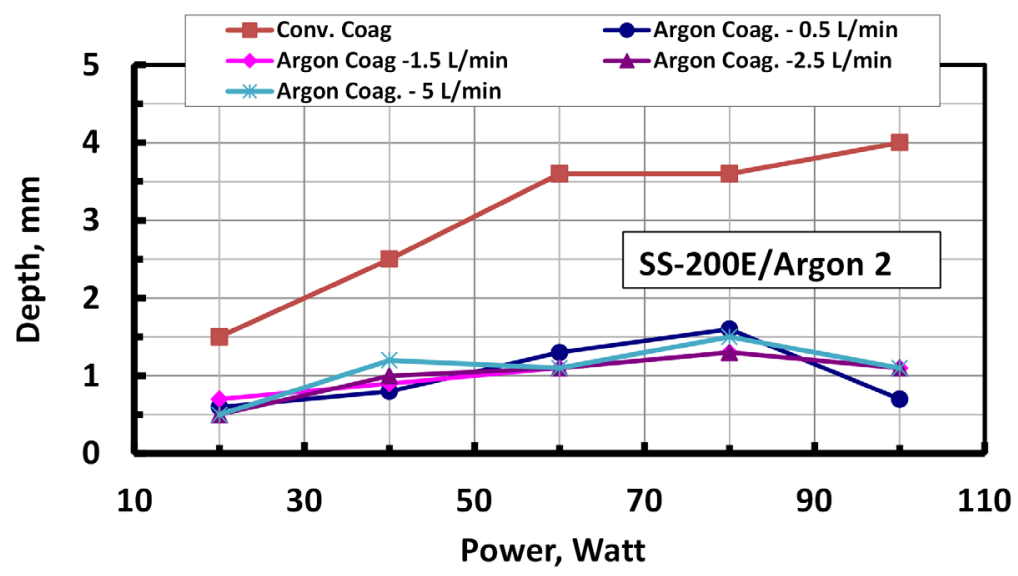

FIG. 8: Depth of eschar in Coagulation mode using SS-200E/Argon 2 
around $0.5 \mathrm{~L} / \mathrm{min}$ ). This in turn results in a larger spread plasma column and therefore larger area of plasma contact with tissue, while there is smaller penetration capability inside the tissue. Therefore, the transition to Argon Coagulation mode led to reducing power penetration in depth and redistributing it along the tissue surface. This explains the larger diameter and smaller depth of eschar observed experimentally at the transition to Argon Coagulation mode. Following increase of argon flow does not change the plasma dynamics significantly and thus the injury size remains fairly unchanged. Note that the tissue heating measuring methodology used in this work was not sensitive enough to resolve local power redistribution. Fair independence of tissue heating on gas flow indicates a similar amount of power being deposited into tissue regardless of argon flow rate.

The injury sizes produced at typical gentle operation parameters utilized in surgical procedures (namely $20 \mathrm{~W}, 2.5-3 \mathrm{~L} / \mathrm{min}$ ) are shown in Fig. 10. One can see that for both
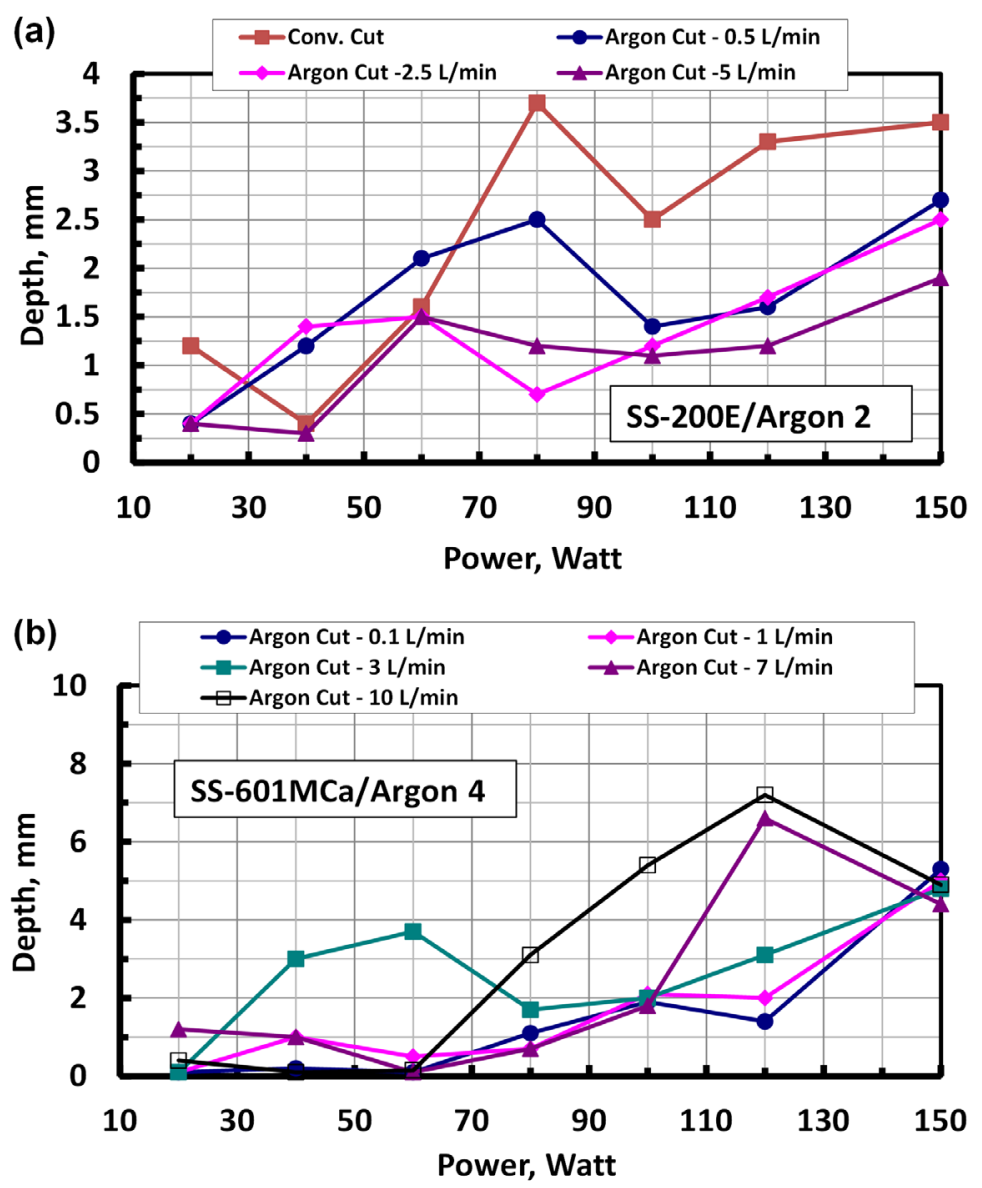

FIG. 9: Depth of eschar in Cut mode using (a) SS-200E/Argon 2; (b) SS-601MCa/Argon 4 

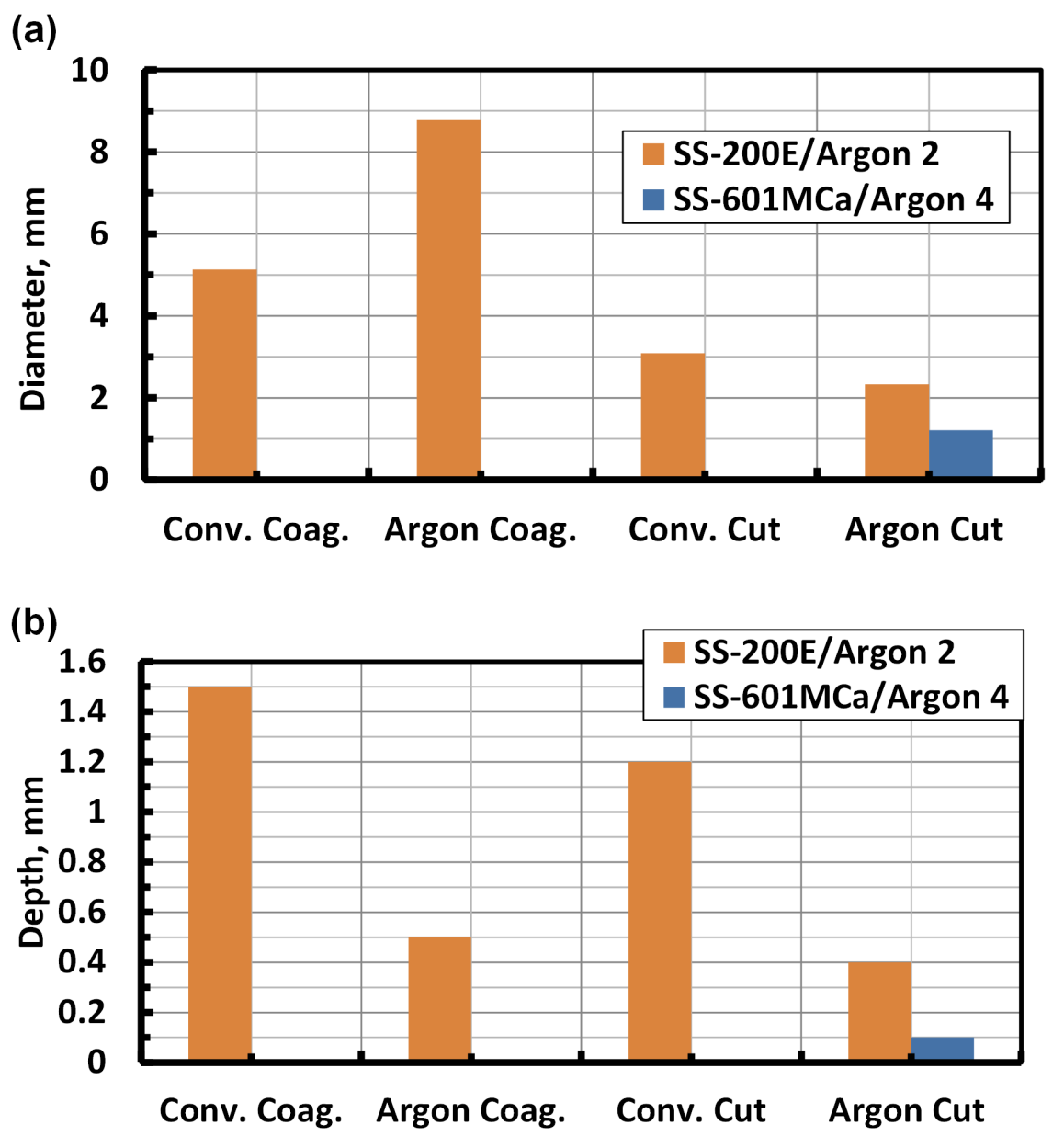

FIG. 10: Size of injury in different operation modes of SS-200E/Argon 2 and SS-601MCa/Argon 4 for power $20 \mathrm{~W}$ and flow 2.5-3 L/min: (a) diameter of escha; (b) depth of eschar

electrosurgical devices Argon Cut mode causes minimal depth and diameter of eschar. The results indicate that tissue cutting using Canady Vieira Hybrid Plasma ${ }^{\mathrm{TM}}$ Scalpel is virtually noninvasive producing very small eschar around the cut, namely $<0.5 \mathrm{~mm}$ in depth and 1-2 mm lateral spread.

\section{CONCLUSIONS}

Plasma length, tissue heating, and injury size were measured for different operational 
conditions of the SS-200E/Argon 2 and SS-601MCa/Argon 4 electrosurgical systems. It was found that plasma length, tissue temperature, and injury size increase with applied power. Transition from Conventional to low flow Argon Coagulation mode $(<0.5 \mathrm{~L} / \mathrm{min})$ led to more sustainable discharge and reduced power penetration in depth while redistributing it along the tissue surface causing decrease of injury depth and increase of eschar diameter. A further increase of gas flow to $>0.5-1 \mathrm{~L} / \mathrm{min}$ did not result in significant change of the eschar and plasma column size. Both electrosurgical systems operating in Argon Cut yield minimal size of injury compared to Conventional Cut, Coagulation, and Argon Coagulation.

\section{ACKNOWLEDGMENTS}

This work is supported by the Jerome Canady Research Institute for Advanced Biological and Technological Sciences, Benefit LLC. The authors acknowledge Gilberto Mangioni, MD, from Laboratorio de Patologio Cirurgica Citopatologia, Ribeirao Preto, SP, Brazil for help with pathological analysis.

\section{REFERENCES}

1. Fridman G, Friedman G, Gutsol A, Shekhter AB, Vasilets VN, Fridman A. Appl Plasma Med, Plasma Process. Polym. 2008;5:503-33.

2. usmedinnovations.com [homepage on the Internet]. US Medical Innovations; c2013 Available from: http://www.usmedinnovations.com.

3. Canady J., Wiley K, Ravo B. Argon plasma coagulation and the future applications for dual-mode endoscopic probes, Rev Gastroenterol Disord. 2006;6:1-12.

4. Raizer YP. Gas discharge physics. Berlin: Springer-Verlag; 1991. 
